\title{
Studying BHIM App Adoption using Bass Model: An Indian Perspective
}

\author{
P. K. Kapur \\ Center for Interdisciplinary Research, \\ Amity University, Noida, India. \\ E-mail: pkkapur1@gmail.com \\ Himanshu Sharma \\ Department of Operational Research, \\ University of Delhi, Delhi, India. \\ E-mail: himanshusharma.du.or@gmail.com \\ Abhishek Tandon \\ Department of Research, \\ Indian Council of Social Science, Delhi, India. \\ Corresponding author: abhishektandon@ @sscbsdu.ac.in \\ Anu G. Aggarwal \\ Department of Operational Research, \\ University of Delhi, Delhi, India. \\ Email: anuagg17@gmail.com
}

(Received March 23, 2019; Accepted August 27, 2019)

\begin{abstract}
Today, even a small street vendor in India provides the customer an option to pay electronically, using their wireless device. The businesses are aware that consumers are increasingly using smartphones to make payments for goods and services. Two types of mobile payments have been introduced by Indian retailers: wallet based and UPI (unified payments interface) based. With the government encouraging its cashless economy drive, it is backing UPI based mobile payment apps. Since earlier researchers studied the mobile payment adoption intention empirically, this study attempts to provide a mathematical model for adoption. The Bass model is used to study time based adoption pattern. Regression analysis was used to estimate the model parameters on BHIM app dataset, a UPI based government initiative. Findings show that the data fits the model well and the effect of coefficient of imitation is greater than that of innovation. Finally, discussions based on the results and implications for practitioners are provided. Future studies may use other extended versions of Bass model.
\end{abstract}

Keywords- Mobile commerce, Mobile payments, Innovation diffusion theorem, Bass model, BHIM App.

\section{Introduction}

Driven by affordable price of smartphones along with technological advancements in the telecom industry has encouraged people to adopt mobile commerce (m-commerce). Heeding on to the mobility feature which differentiates it from its PC-based counterpart (electronic commerce), it helps in booking tickets, processing transactions, online shopping, and many more tasks; anytime and anywhere. According to a report, the number of smartphone users in India is estimated to be 337 million in 2018, and this number is expected to reach 490.9 million by 2022 (statista, 2018). Moreover, the m-commerce sales revenue in the Indian context is foresighted to reach 36 billion USD by 2020 from the mark of 6 billion USD in 2015. This may be attributed to the advantages 
International Journal of Mathematical, Engineering and Management Sciences

Vol. 5, No. 1, 120-135, 2020

https://doi.org/10.33889/IJMEMS.2020.5.1.011

experienced under m-commerce such as instantaneity, ubiquity, localization, personalization, and feedback mechanism. All this is possible due the popularity of electronic gadgets such as smart phones, note books, and tablets, along with availability of good connectivity and speed of the internet.

With the Indian government introducing demonetisation and launching various schemes to make the country a 'cashless economy', the process of making payments through online modes have picked up pace in recent times. These initiatives have been stated as six-point action plan by the Indian government (Express, 2018) defined as follows: (1) Making it compulsory for government offices to set up QR codes for accepting online transactions; (2) Offices can issue intend to customers in return for their digital payments; (3) Encouraging all payments through bank linked mobile apps; (4) Introducing digital payments for toll taxes (FASTag); (5) All utility bills to contain QR code; (6) Introducing common mobility cards for making ticket payments in government owned vehicles. This has led to a need for operating a payment app through smartphones with the help of which transactions for ticketing, shopping, bill payments, cab booking, and many more services can be made at customer's convenience. According to a recent report, by the end of 2018, 73.9 billion people i.e. 7.6\% of the total Indian population adopted mobile payment apps (cio.in, 2018). Along with the government, many companies are squeezing their way into Indian mobile payment industry, in order to share a meat of revenues generated through mobile commerce.

Two types of payment apps have been established by developers namely wallet and UPI (unified payments interface) (Daştan and Gürler, 2016).Wallets make use of the money stored in a firm's app which can be later used for making payments, whereas, UPI based apps support IMPS (Immediate Payment Service), that makes use of bank account details of the operator and helps in instantly transfer of money. After the demonetisation period in India, the UPI based apps have completely outperformed the wallet-based apps. It has been reported that in India the UPI based transactions have shown a $30 \%$ upsurge in 2018, with 30 million transactions summing to 5,293 crore worth in Indian rupees (economictimes.com, 2019).This may be attributed to four major differences between these two mobile payment categories. Firstly, UPI simplifies peer-to-peer transaction whereas wallet requires multiple channels, as money is first transferred from bank account to wallet and then from wallet to the payee. Secondly, wallet payments require KYC (know your customer) details, which is not necessary for UPI as it is equivalent to internet banking through phones. Thirdly, these days even the firms using wallet-based apps are considering it beneficiary to adopt UPI. Lastly, wallets encounter the issue of interoperability as wallet payments require the payee to necessarily have a wallet of the same company, which is not so in UPI as money is directly transferred to the bank of payee. Even though the concept of UPI based payments was introduced by the government with BHIM (Bharat Interface for Money) app, other companies such as Paytm, Flipkart-owned PhonePe, and Google Pay, are trying to create their share.

Mobile payments refer to "the use of a mobile device to conduct a payment transaction in which money or funds are transferred from a payer to a receiver via an intermediary or directly without an intermediary" (Jaradat and Faqih, 2014). Since it involves a payment process, it is often confused with mobile banking. Mobile banking provides the ability to perform bank facilities exclusively for its account holders. On the other hand, mobile payments are the payment services provided to retailers where the customers and merchants coexist in the presence of abundant banks and telecom operators (Khalilzadeh et al., 2017). Even though the banks, merchants, and 
International Journal of Mathematical, Engineering and Management Sciences

Vol. 5, No. 1, 120-135, 2020

https://doi.org/10.33889/IJMEMS.2020.5.1.011

telecom operators are continuously contributing towards mobile payment services, still the adoption intention is low among the potential purchasers (Kapoor et al., 2015). Researchers support the statement by arguing that it may be due to influential factors such as trust, convenience, compatibility, affordability, and many more. Previous studies in the ten years have emphasized on evaluating the measures that lead to adoption of mobile payment services and its continuance (Humbani and Wiese, 2018).

Though much of the earlier studies attempted to evaluate the adoption measures using TAM (technology acceptance model) (Davis et al., 1989), TRA (theory of reasoned action) (Ajzen and Fishbein, 1980), DOI (diffusion of innovation) (Rogers, 1983), UTAUT (unified theory of acceptance and use of technology) (Venkatesh and Davis, 2000), UTAUT2 (Venkatesh et al., 2003); an empirical investigation was provided (Yang et al., 2015). This study provides a mathematical model based on Bass model to study the adoption behaviour of customers for mobile payment applications. Bass model proposes an innovation - diffusion process which depends on the timing of adoption of the potential buyers (Bass, 1969). Bass model acts as a diagnostic tool to determine whether the failure of new products is due to market factors or mistakes by the organization in an otherwise favorable environment. Further, Bass model provides for analysis of a moving target market approach and a comparison of effects of that approach to a standard mass marketing effort (Kapur et al., 2010). This is possible because the Bass model allows for prediction of future adoption behavior from partial adoption data (Daim and Suntharasaj, 2009; Jiang and Jain, 2012; Chikouche et al., 2019). The model is mainly applicable for infrequently purchased products. This assumption became the motivation of our study as an application is installed by a browser only once in his smartphone, which can be considered as a situation where there is no repeat purchase. Bass divided the adopters into innovators and imitators based on the influence of their purchasing decision. According to Jiang et al. (2018), the best quality of the model is that it can be modified, extended, or applied in accordance to specific circumstantial problems. Therefore, Bass model is one of the best models for first-purchase products or technology, which is derived using hazard rate function (Chanda and Das, 2015).

Diffusion theory provides an excellent framework that explains the factors that result in potential adoption as well as the effect of their attributes. The Bass model is asserted to be the most successful and parsimonious model for studying the adoption of various technological innovations (Chanda and Bardhan, 2008). The Bass model overcomes the shortcomings of Roger's theory and its extensions by considering different number of adopters for each innovation and also withholding the strength of the theory such as predicting and linking continuous acceptance of a new innovation (Daim and Suntharasaj, 2009). Also, Bass model works well for major (brand-new) or discontinuous (one-of-a-kind) innovations as well as for minor (variations of an existing innovation) or continuous (building upon an existing innovation) types of innovations (Jiang and Jain, 2012).The model fits a two-parameter equation to project adoption over time as an S-shaped curve. The first parameter corresponds to an "innovator", who tries to adopt the technology in its initial life cycle stage. They are willing to take the risk of adopting a new technology, and thus are not affected by others in the social system. Since people gather knowledge about the technology through various mass media or advertising mediums such as television, radio, and internet; so the corresponding parameter represents coefficient of external source of information. The other parameter is for an "imitator", who is influenced by other members of the social system in the timing of adoption of a new technology. Since they have a social influence in the form of interpersonal communication or word-of-mouth (WOM) in their 
International Journal of Mathematical, Engineering and Management Sciences

Vol. 5, No. 1, 120-135, 2020

https://doi.org/10.33889/IJMEMS.2020.5.1.011

adoption decision; the corresponding parameter is termed as coefficient of internal source of information. Previous studies involving Bass model quote that the estimated value of coefficient of innovation outperforms the coefficient of imitation (Bass, 1969; Jiang and Jain, 2012; Fan et al., 2017); this embarks the importance of social influence along with EWOM.

WOM may be defined as "all informal communications directed at other consumers about the ownership, usage or characteristics of particular goods or their sellers" (Mauri and Minazzi, 2013; Wen et al., 2018). Theories related to WOM have gained popularity among the social science studies. But, the advancements in internet technology have forced it to have a makeover in online framework, namely EWOM (electronic word-of-mouth). Practitioners have observed that satisfied (dissatisfied) customers generally tend to spread positive (negative) words regarding the product/service (Cui et al., 2012). However, electronic mediums have accelerated the diffusion rate, and resulted in more influential impact on potential purchasers (Yang et al., 2018). The feedback posted by previous purchasers may be spread by closely knit people who have strong ties with the reader i.e. family or close friends, whereas they may also be spread by those who share weak ties with the reader i.e. acquaintances. Therefore, the developments in technology and the masses having access to these services, the process of spreading messages through offline modes have experienced a digital transformation towards EWOM. EWOM is believed to be more trustworthy, helpful, reliable, and credible source of information in comparison to companygenerated content (Li et al., 2013; Mauri and Minazzi, 2013; Xiang et al., 2015; Zhou et al., 2014).

Therefore, the paper aims to use the parsimonious Bass model to check the consistency of BHIM app dataset, a UPI based app introduced by government of India post demonetisation to accomplish its cashless economy drive. For this we check validity of the data fitting the infamous Bass adoption model and obtain the estimated value of the innovation and imitation coefficient. This paper is distinguished from the previous studies as much of the studies were empirical using inputs through surveys and focus groups whereas this study utilizes the secondary data available on government website. Also, much of the studies underlined the concept of mobile wallets whereas we base our study on UPI based app. The remaining paper is documented as: next section provides a detailed literature regarding mobile payment services; Section 3 describes the model along with its assumptions; the data description and its analysis is given in Section 4; managerial implications regarding the findings are presented in Section 5; and finally limitations and future scope of the study is provided in last section.

\section{Related Literature}

\subsection{Mobile Payment Services}

A mobile payment service (MPS) is defined as "any type of individual or business activity involving an electronic device with a connection to a mobile network, enabling the successful completion of an economic transaction" (Slade et al., 2015). First instance of mobile payment was observed in 1997, when Coca Cola allowed the customers to make a purchase using vending machine and pay using wireless device (Morosan and DeFranco, 2016). Since then many studies have been conducted using various marketing models that focus on MPS. Mallat (2007) used focus group study to find key determinants of MPS adoption based on DOI theory. According to him, relative advantage, compatibility, and trust had a positive influence over adoption whereas complexity, cost, network externalities, and payment system security put negative impact. Balocco et al. (2008) performed an exploratory study to find the adoption determinants. They reported that easiness and versatility of use, an easier management of the solution, visibility, and 
International Journal of Mathematical, Engineering and Management Sciences

Vol. 5, No. 1, 120-135, 2020

https://doi.org/10.33889/IJMEMS.2020.5.1.011

cost reduction put positive impact whereas consolidated substitutive products and costinefficiency had negative. Moreover, they found regulations and value chain relationships to be adoption barriers for users. Another study was conducted that used structural equation modeling (SEM) on TAM elements (Eze et al., 2008). The findings showed that trust, perceived ease of use, and perceived usefulness positively affect MPS adoption.

A comparative study was conducted for performance evaluation of five MPS like Interactive Voice Response, Short Message Service, Wireless Application Protocol, One Time Password, and Near Field Communication (NFC) (Massoth and Bingel, 2009). Results showed the dominance of NFC based payments in comparison to others. Ghezzi et al. (2010) performed an empirical analysis combining census and sixteen case studies to find the key determinants of MPS adoption process. They found that apart from positive and negative influencers, still there exist some barriers that hinder adoption. Lu et al. (2011) used SEM approach to study adoption under trust - transfer and DOI theory. The DOI elements were further divided into positive and negative valence (as per valence theory). Findings showed similar impacts on adoption as per their nature of valence. An SEM based conceptual framework consisting of elements of three theories namely behavioral beliefs, social influences, and personal traits has also been taken up (Yang et al., 2012). Results show significant positive impact of all the three factors on MPS adoption. Amoroso and Magnier-Watanabe (2012) combined TAM and UTAUT elements along with attractiveness of alternatives as determinants of adoption. Based on literary analysis, they found significant impact of these variables over adoption.

Another model combining information system (IS) theory and flow theory was proposed to study MPS adoption continuance (Zhou, 2013). SEM approach was applied for testing the model and the results showed that system quality, service quality, and information quality (i.e. elements of IS) positively affects flow, which in turn affects continuance intention. Liébana-Cabanillas et al. (2014a) considered extended TAM model consisting of external influences, ease of use, attitude, usefulness, trust, and risk; as well as moderating effect of age. SEM analysis showed positive affect for all the variables except risk. Similar research was conducted to study MPS under virtual social networks by extending TRA and TAM theories; with the moderating effect of user's experience (Liébana-Cabanillas et al., 2014b). Findings using SEM approach validated the hypothesized model. Shaw (2014) took TAM theory with an additional variable: informal learning; with trust as a mediator of informal learning. Partial least squares (PLS) approach was applied to test the conceptual model and it successfully validated the assertions.

Another research considering UTAUT along with innovativeness and risk was conducted with the help of SEM approach (Slade et al., 2015). Findings show support for performance expectancy, social influence, innovativeness, and perceived risk; but did not support effort expectancy. Koenig-Lewis et al. (2015) combined TAM and UTAUT2 to study the MPS adoption intention. SEM results showed support for perceived usefulness, perceived risk, and high knowledge level; but did not support PEOU and perceived enjoyment. Slade et al. (2015) extended UTAUT2 by adding trust and risk in their conceptual framework for MPS adoption. Findings based on regression analysis showed support for performance expectancy, habit, hedonic motivation, and social influence; whereas not for effort expectancy, facilitating conditions, and price value. Another interbank adoption model combining variables under three popular theories namely DOI, Tornatzky and Klein's study, and PCI theory was proposed (Kapoor et al., 2015). Logistic regression analysis showed support for most of the assertions. 
International Journal of Mathematical, Engineering and Management Sciences

Vol. 5, No. 1, 120-135, 2020

https://doi.org/10.33889/IJMEMS.2020.5.1.011

A conceptual framework combining UTAUT2 and DOI theories along with perceived risk was built to study MPS adoption intention (Oliveira et al., 2016). Using SEM approach, the model showed support for compatibility, perceived technology security, performance expectations, innovativeness, and social influence. Daştan and Gürler (2016) formulated an adoption model based on extended TAM theory. SEM results showed support for perceived trust, perceived mobility and attitudes; but did not accept perceived usefulness and perceived ease of use. Another adoption model combining elements of TAM, TCE, IS, and valence theory; along with trust was formulated (Gao and Waechter, 2017). PLS approach showed acceptance of most of the assertions considered in the study. Humbani and Wiese (2018) proposed MPS adoption model based on TRI theory. As per the regression analysis results, model accepted positive impact of convenience and compatibility, whereas negative for risk, cost and insecurity. Another model covering TAM along with social factors was proposed; with moderating effect of user's gender, age and experience level (Liébana-Cabanillas et al., 2018). SEM analysis showed support for all the considered hypotheses.

\subsection{MPS in Indian Context}

The concept of mobile payment services (MPS) in India picked pace after the postdemonetization period i.e. after 2016. Being a developing economy, the awareness related to internet and its usage is less diffused (Sheetal et al., 2019). In the midst of the cashless economy drive initiated by the Indian government, few retail firms such as Flipkart, Amazon, Snapdeal, Shopclues, and many others stopped cash-on-delivery (COD) payment mode of payment. This resulted in reduced revenues, but, they encouraged consumers to adopt payments through debit and credit cards, thereby inculcating the card culture or 'plastic money' (Garg and Panchal, 2016). Post demonetization, NPCI, act as the umbrella organization for all retail payment systems in India has taken up a new initiative of implementing UPI to simplify and provide a single payment application (Thomas and Chatterjee, 2017). Scant studies have focused on mobile payments in India context.

A study was performed to observe the relationship between adoption readiness, personal innovativeness, perceived risk, and intention to use mobile payments (Thakur and Srivastava, 2014). Based on 774 responses obtained from Indian respondents, SEM was used to test the relationships. The result supported most of the considered hypotheses. Thakur (2013) studied the MPS adoption behavior for two metropolitan cities of India. Extended TAM model constructs namely performance expectancy, effort expectancy, social influence and facilitating conditions were utilized for studying the adoption intention. The conceptual model was validated by applying PLS on data obtained from 146 respondents. Another study was conducted to see the influence of mobile money among poor citizens of India (Chauhan, 2015). A model was hypothesized using TAM constructs along with trust. On the basis of 225 responses obtained, PLS-SEM results embarked the key role of trust in the mobile payment adoption intention among poor-sections of India. Sivathanu (2019) performed a study to investigate the actual usage (AU) of digital payment systems by the consumers during the period of demonetization in India. Combining the constructs of UTAUT2 and innovation resistance theory, PLS-SEM approach was used to validate the hypotheses on a data obtained through 766 respondents residing in India. Another study was conducted using extended TAM model constructs and hypothesized model was validated by applying SEM on 381 responses (Shankar and Datta, 2018). Research findings indicated that The results exhibit that PEOU, PU, trust, and self-efficacy have a significant positive impact on m-payment adoption intention, whereas, subjective norms and personal innovativeness have no significant impact. Sinha et al. (2019) performed another empirical study 
International Journal of Mathematical, Engineering and Management Sciences

Vol. 5, No. 1, 120-135, 2020

https://doi.org/10.33889/IJMEMS.2020.5.1.011

post demonetization consisting of 600 respondents from four cities in India. SEM results showed that cash shortage due to demonetization spurred mobile payment adoption but usage and retention remained low.

\subsection{Research Motivation}

All the above mentioned research works were qualitative in nature and predominantly used questionnaire as the research instrument. These studies ascertained the determinants of MPS adoption and studied the moderating effects of various demographic factors. They are based on well-established theories of customer adoption behavior, mainly based on Roger's DOI Theory. In this paper, we apply Bass Innovation Diffusion model to study MPS adoption process. The Bass model overcomes the shortcomings of Roger's theory by considering different number of adopters for each innovation and also withholding the strength of the theory such as predicting and linking continuous acceptance of a new innovation. Also, Bass model works well for major (brand-new) or discontinuous (one-of-a-kind) innovations as well as for minor (variations of an existing innovation) or continuous (building upon an existing innovation) types of innovations. Much of the previous studies were empirical using inputs through surveys and focus groups whereas this study utilizes the secondary data available on government website. As per the knowledge of authors, this study is first in studying MPS adoption for apps using mathematical model. Also, earlier studies majorly underlined the concept of mobile wallets whereas we base our study on UPI based app. We have validated the model on MPS data for BHIM app, an UPI based MPS initiative by Government of India. This study would be helpful to the policymakers as well as marketing strategists to design UPI-based apps. In the next section we provide a brief overview of Bass External-Internal Influence model, its assumptions, and mathematical expressions. Figure 1 describes the research methodology pursued in this paper.

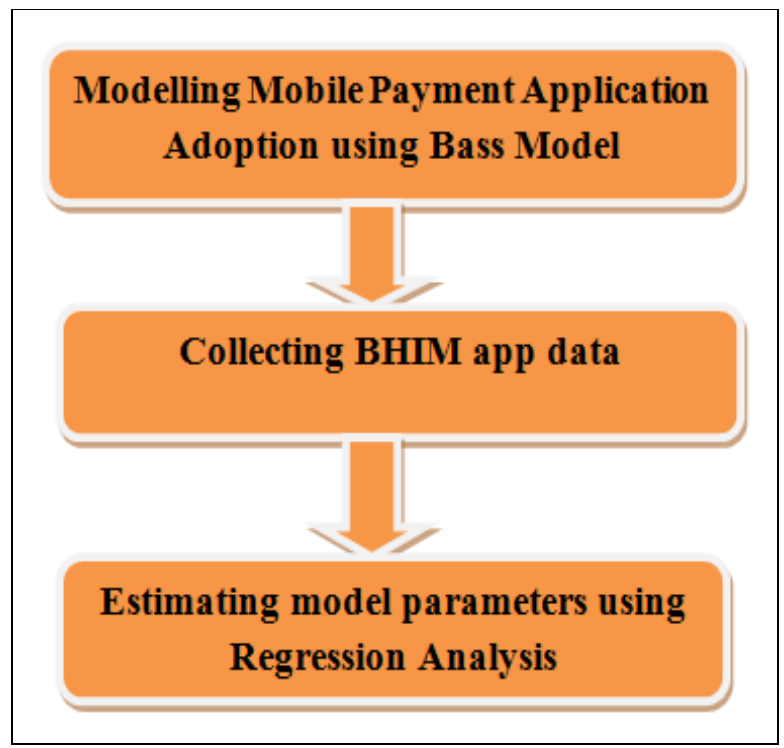

Figure 1. Research methodology 
International Journal of Mathematical, Engineering and Management Sciences

Vol. 5, No. 1, 120-135, 2020

https://doi.org/10.33889/IJMEMS.2020.5.1.011

\section{Bass Model}

The Bass model is an important concept in understanding the time based adoption pattern for new products or innovations. As per the model, except for innovators, other adopters get influenced from the members of the social system, in the timing of adoption. It is applicable for consumer durables i.e. products/technologies which are not frequently bought. Therefore, the Bass Model states that the probability that an individual or firm will adopt a new technology is dependent on the proportion of previous adopters through the forces of innovation and imitation. Next we discuss the model.

\subsection{Model Assumptions}

- Initially $m$ numbers of adoptions of the application are made.

- The probability of initial purchase at $T$ given that no adoption has yet been made is a linear function of previous adopters.

- Initial purchases are made by both innovators and imitators; however the difference lies in the influential factors for adoption.

- The influence of innovators will be larger at first and is expected to decrease monotonically over time.

- The coefficient of innovation is denoted by $p$ whereas coefficient of imitation is represented by $q$.

\subsection{Model Development}

The likelihood of adoption at time $T$ given that no adoption has yet been made is given by,

$\frac{f(T)}{1-F(t)}=P(T)=p+\frac{q}{m} Y(T)=p+q F(T)$

where $f(T)$ is the likelihood of adoption at $T$ and $F(T)=\int_{0}^{T} f(t) d t$ with $F(0)=0$.

$f(T)=p[1-F(T)]+q F(T)[1-F(T)]$

$f(T)=p+(q-p) F(T)-q[F(T)]^{2}$

Few individuals make a decision to adopt a technological innovation independent of others in the social system. These individuals are termed as innovators. Apart from them, few adopters are influenced in their decision making through inter-personal communication channels. These are termed as imitators (Jiang and Jain, 2012). The first term in equation (2) represents app users who are not influenced in their adoption time by the number of previous installers. Whereas, the second term in equation (2) are influenced in their adoption time by existing app users. Therefore, the first term represents the "innovators" and the latter represents "imitators". The coefficients $p$ and $q$ corresponds to the diffusion of innovations through mass media and interpersonal communication respectively and thus are correspondingly termed as external and internal source of information, respectively. On solving the above equations and applying the initial condition $F(0)=0$, we get the cumulative diffusion function as,

$F(T)=\frac{1-e^{-(p+q) T}}{1+\frac{q}{p} e^{-(p+q) T}}$

and on differentiating we get the non-cumulative diffusion function 
International Journal of Mathematical, Engineering and Management Sciences

Vol. 5, No. 1, 120-135, 2020

https://doi.org/10.33889/IJMEMS.2020.5.1.011

$f(T)=\left(\frac{(p+q)^{2}}{p}\right)\left[\frac{e^{-(p+q) T}}{\left(\frac{q}{p} e^{-(p+q) T}\right)^{2}}\right]$

The point of inflexion which represents the time at which the number of adopters is at peak is given by

$T^{*}=-\frac{1}{(p+q)} \ln \left(\frac{p}{q}\right)$

In next section, we describe the relevance of Bass model to the adoption data of BHIM app and goodness of fit.

\section{Data Description and Analysis 4.1 Why BHIM App?}

Bharat interface for money (BHIM) is a payment application which makes use of unified payment interface (UPI) for transactions. The app was launched on 11 $1^{\text {th }}$ April, 2016 in Mumbai, by the Indian Prime Minister in order to support his "Digital India" campaign. The app is helpful for people who wish to process a safe and secure online transaction through their smartphone supporting android or iOS operating systems. The initiative was taken by the government to provide various benefits to the users such as (i) It is possible to use it using a smartphone as well as a feature phone; (ii) It is not necessary to have an functional internet banking option while using; (iii) The transaction for shopping purposes can be easily made using a bank account linked to the Aadhar card (economictimes.com, 2018). Currently, BHIM app has been adopted by 92 banks and the number of applications being downloaded is showing a growing trend. The national payments corporation of India (NPCI) reported a $15 \%$ rise in number of transactions and 9\% increase in transaction value till June 2018 (inc42.com, 2018). In order to make the app competent with private competitors, the government is encouraging central ministries such as railways and consumer affairs, departments, states, and union territories to make their transactions through it.

The data was extracted from an open access website https://www.npci.org.in/bhim-analytics. The data includes the name and number of banks that have adopted transactions through BHIM app, number of app downloads (Volume in millions), and the amount of retail generated (Indian rupees in 10 millions). Time interval of the data is from December 2016 i.e. when the app was launched in India, to December 2018.

\subsection{Data Analysis}

Non-linear regression is used to estimate the parameters of the Bass model. Table 1 represents the regression analysis results. Moreover, in order to check the goodness of fit of the model, the coefficient of determination value and mean square error (MSE) are used and their values are given in Table 2. From these values we may note that the model fits the data well. Figure 2 represents the model validation results graphically.

Table 1. Parameter estimation results

\begin{tabular}{|c|c|c|c|c|}
\hline Parameter & Estimate & Std. Error & \multicolumn{2}{|c|}{ Interval } \\
\cline { 4 - 5 } & & & Lower & Upper \\
\hline$N$ & 45.372 & 10.500 & 23.595 & 07.148 \\
\hline$p$ & 0.043 & 0.007 & 0.029 & 0.059 \\
\hline$q$ & 0.058 & 0.066 & -0.080 & 0.196 \\
\hline
\end{tabular}


International Journal of Mathematical, Engineering and Management Sciences

Vol. 5, No. 1, 120-135, 2020

https://doi.org/10.33889/IJMEMS.2020.5.1.011

Table 2. Goodness of fit results

\begin{tabular}{|l|c|l|l|}
\hline \multicolumn{1}{|c|}{ Measure } & \multicolumn{1}{|c|}{ Formula } & Description \\
\hline $\begin{array}{l}\text { Coefficient of } \\
\text { Determination }\end{array}$ & $R^{2}=\frac{\text { Explained Sum of Squares }}{\text { Total Sum of Squares }}$ & $\begin{array}{l}\text { The higher the value, the better the } \\
\text { model fits the data }\end{array}$ & 0.925 \\
\hline Mean Square Error & $M S E=\frac{\sum\left(y_{i}-\widehat{y}_{t}\right)^{2}}{n} ; n$ is total number of observations & $\begin{array}{l}\text { The lower the value, the better the } \\
\text { model fits the data }\end{array}$ \\
\hline
\end{tabular}

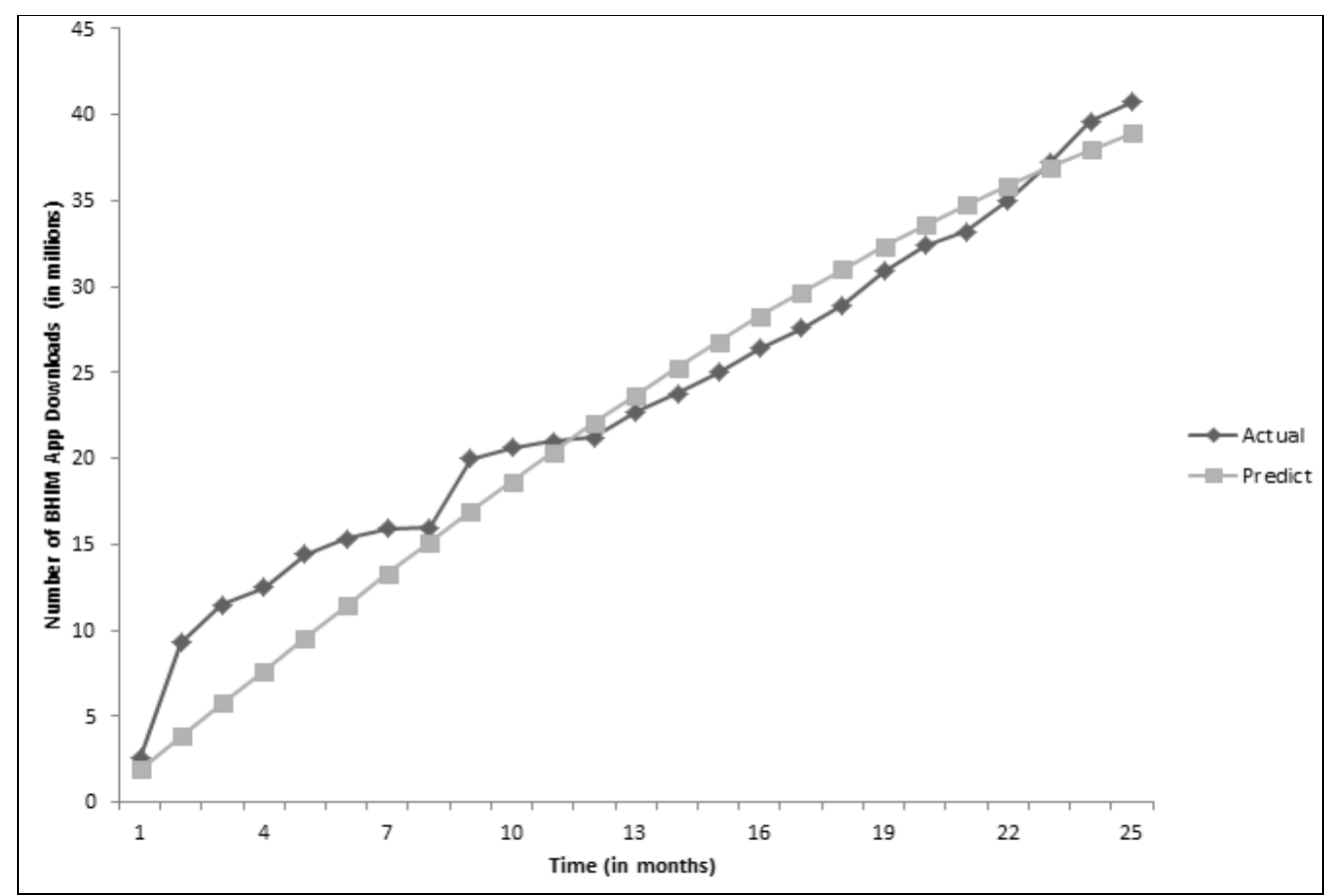

Figure 2. Adoption growth rate for BHIM App

\section{Discussions and Research Implications}

The non-linear regression analysis results show that the Bass model provided appropriate goodness of fit to the app data. As per the Bass model, the value of prepresents the percentage of population that learns about the new technology through mass media and will adopt it, whereas the $q$ value provides with the percentage of population that learns about the technology by wordof-mouth of the earlier users. The estimated value of $q(=0.058)$, which represents the coefficient of imitation, is higher than the estimated value of $p(=0.043)$, the coefficient of innovation. Also, the $q / p$ ratio is also greater than one. It implies that more and more people has adopted BHIM app under the influence of interpersonal recommendation while less number of people has adopted the UPI-based mobile payment under the influence of external media. This suggests the marketers to utilize the various social platforms for influencing the potential installers and must focus their marketing strategies towards these interfaces in comparison to external media. These results are consistent with other technology-based product diffusion study (Eze et al., 2008; Lu et 
International Journal of Mathematical, Engineering and Management Sciences

Vol. 5, No. 1, 120-135, 2020

https://doi.org/10.33889/IJMEMS.2020.5.1.011

al., 2011; Slade et al., 2015; Daştan and Gürler, 2016; Gao and Waechter, 2017). Also, the cumulative distribution of Bass model portrays an S-shape curve.

Therefore, the emergence of digital era has instilled the need for marketers to assess the feedbacks of the customers who own the technology or have prior knowledge about it. This has popularized the concept of electronic word-of-mouth (EWOM) or online customer feedback (OCF).All the mobile payment apps provide the downloaders and users a platform where they can post their reviews which are accessible to the potential users, even if they are not socially connected. The business managers must keep a track of these feedbacks and reply with appropriate solution, especially in case of a complaining review. Moreover, the estimated value of $N$ (= 45.372 in millions) represents a high population of potential users of BHIM app in the future. BHIM app was launched to encourage 'cashless movement' in India. The app supports swift and secure payment through a bank-to-bank transaction. According to a report generated by CUTS International, the Union Budget of 2018 introduced two schemes to endorse BHIM namely cashback scheme and customer referral bonus scheme (International, 2018). Under cashback scheme, for credit transactions between 20-50merchants will receive a cashback of Rupees 50 by month end. Above 50 credits from at least 20 unique customers and minimum transaction of Rupees 25 each, merchants will receive a cashback of Rupees 2 per transaction up to Rupees 950. The maximum cashback in this case is Rupees 1000 per month. Under the customer referral bonus scheme, each referrer and each new referee is eligible for a bonus of Rupees 25 . These promotional schemes administered by Ministry of Electronics and Information Quality had a total outlay of Rupees 45 crore within six months period (April 2017 to October 2017).These monetary figures indicate the growing popularity of m-payment apps among Indian people and signify the bright future ahead for mobile enabled payment schemes in near future. Again, our this finding goes well with other previous studies (Ghosh, 2017; Kumar et al., 2018; Passah and Kumar, 2019).

\section{Conclusion, Limitations, and Future Scope}

With the recent advancements in telecom industry and the Indian government supporting the drive to make India a cashless economy, the popularity of mobile payment services has increased. Mainly two types of services have been noticed over the years which are wallet-based and UPI based. Since the mobile wallet reserves the money for future transactions, on the other hand, UPI makes use of interbank transactions with the help of account details of the purchaser. Here we aim to discuss the adoption intention of mobile payment app across Indian population with the help of a mathematical model. This feature differentiates the study from previous works which performed empirical studies by considering variables under adoption theories such as DOI, TAM, TRA, UTAUT, UTAUT2, and many more. The mathematical considered here is the Bass model. It is asserted to be the best models for first purchase technology which depends on the hazard rate function. A well-known government initiative in the mobile payment services is the BHIM app, which is a UPI based application. This dataset was used to fit the bass model. The regression results showed that the model fitted the data well as well as the estimates of the parameters were acceptable. Moreover, higher coefficient of imitation value showed the importance of social interaction or word-of-mouth as compared to coefficient of innovation which depends on advertising.

Still the model encounters some limitations. The study makes use of only Bass model. In future its extended versions incorporating price or successive generations may be implemented. The app dataset is taken from Indian perspective; however findings may not be generalized for other 
International Journal of Mathematical, Engineering and Management Sciences

Vol. 5, No. 1, 120-135, 2020

https://doi.org/10.33889/IJMEMS.2020.5.1.011

emerging economies. This can be tackled in future studies by conducting cross border analysis. The results showed the importance of WOM, which may be handled in upcoming researches by incorporating online review text and ratings into the proposed model.

\section{Conflict of Interest}

The authors confirm that there is no conflict of interest to declare for this publication.

\section{Acknowledgement}

This research work was supported by the grants provided by Indian Council of Social Science Research, Delhi, India (File No.: 02/76/2017-18/RP/Major).

\section{References}

Ajzen, I., \& Fishbein, M. (Eds.). (1980). Understanding attitudes and predicting social behaviour (illustrated ed.): Prentice-Hall. Englewood Cliffs, N.J.: Prentice-Hall.

Amoroso, D.L., \& Magnier-Watanabe, R. (2012). Building a research model for mobile wallet consumer adoption: the case of mobile Suica in Japan. Journal of Theoretical and Applied Electronic Commerce Research, 7(1), 94-110.

Balocco, R., Ghezzi, A., Bonometti, G., \& Renga, F. (2008, July). Mobile payment applications: an exploratory analysis of the Italian diffusion process. In 2008 7th International Conference on Mobile Business (pp. 153-163). IEEE. Barcelona, Spain.

Bass, F.M. (1969). A new product growth for model consumer durables. Management Science, 15(5), 215227.

Chanda, U., \& Bardhan, A.K. (2008). Modelling innovation and imitation sales of products with multiple technological generations. The Journal of High Technology Management Research, 18(2), 173-190.

Chanda, U., \& Das, S. (2015). Multi-stage diffusion dynamics in multiple generation high technology products. The Journal of High Technology Management Research, 26(1), 88-104.

Chauhan, S. (2015). Acceptance of mobile money by poor citizens of India: integrating trust into the technology acceptance model. Info, 17(3), 58-68.

Chikouche, S., Bouhouita-Guermech, S.E., Bouziane, A., \& Mostefai, M. (2019). New evolutionary adoption model for innovation diffusion. Journal of Information Technology Research, 12(2), 115-133.

Cui, G., Lui, H.K., \& Guo, X. (2012). The effect of online consumer reviews on new product sales. International Journal of Electronic Commerce, 17(1), 39-58.

Daim, T., \& Suntharasaj, P. (2009). Technology diffusion: forecasting with bibliometric analysis and Bass model. Foresight, 11(3), 45-55.

Daştan, İ., \& Gürler, C. (2016). Factors affecting the adoption of mobile payment systems: an empirical analysis. EMAJ: Emerging Markets Journal, 6(1), 17-24.

Davis, F.D., Bagozzi, R.P., \& Warshaw, P.R. (1989). User acceptance of computer technology: a comparison of two theoretical models. Management Science, 35(8), 982-1003.

Eze, U.C., Gan, G.G.G., Ademu, J., \& Tella, S.A. (2008). Modelling user trust and mobile payment adoption: a conceptual framework. Communications of the IBIMA, 3(29), 224-231. 
International Journal of Mathematical, Engineering and Management Sciences

Vol. 5, No. 1, 120-135, 2020

https://doi.org/10.33889/IJMEMS.2020.5.1.011

Fan, Z.P., Che, Y.J., \& Chen, Z.Y. (2017). Product sales forecasting using online reviews and historical sales data: a method combining the Bass model and sentiment analysis. Journal of Business Research, 74, 90-100.

Gao, L., \& Waechter, K.A. (2017). Examining the role of initial trust in user adoption of mobile payment services: an empirical investigation. Information Systems Frontiers, 19(3), 525-548.

Garg, P., \& Panchal, M. (2016). Study on introduction of cashless economy in India 2016: benefits \& challenge's. Journal of Business and Management, 19(4), 116-120.

Ghezzi, A., Renga, F., Balocco, R., \& Pescetto, P. (2010). Mobile payment applications: offer state of the art in the Italian market. Info, 12(5), 3-22.

Ghosh, A. (2017). Turning India into a cashless economy: the challenges to overcome. Available at SSRN: https://ssrn.com/abstract=2989290 or http://dx.doi.org/10.2139/ssrn.2989290 .

Humbani, M., \& Wiese, M. (2018). A cashless society for all: determining consumers' readiness to adopt mobile payment services. Journal of African Business, 19(3), 409-429.

Jaradat, M.I.R.M., \& Faqih, K.M. (2014). Investigating the moderating effects of gender and self-efficacy in the context of mobile payment adoption: a developing country perspective. International Journal of Business and Management, 9(11), 147.

Jiang, Z., \& Jain, D.C. (2012). A generalized Norton-Bass model for multigeneration diffusion. Management Science, 58(10), 1887-1897.

Jiang, Z., Qu, X., \& Jain, D.C. (2018). Optimal market entry timing for successive generations of technological innovations. MIS quarterly, Forthcoming, 63. Available at SSRN: https://ssrn.com/abstract=3113956.

Kapoor, K.K., Dwivedi, Y.K., \& Williams, M.D. (2015). Examining the role of three sets of innovation attributes for determining adoption of the interbank mobile payment service. Information Systems Frontiers, 17(5), 1039-1056.

Kapur, P., Singh, O., Chanda, U., \& Basirzadeh, M. (2010). Determining adoption pattern with pricing using two-dimensional innovation diffusion model. The Journal of High Technology Management Research, 21(2), 136-146.

Khalilzadeh, J., Ozturk, A.B., \& Bilgihan, A. (2017). Security-related factors in extended UTAUT model for NFC based mobile payment in the restaurant industry. Computers in Human Behavior, 70, 460474.

Koenig-Lewis, N., Marquet, M., Palmer, A., \& Zhao, A.L. (2015). Enjoyment and social influence: predicting mobile payment adoption. The Service Industries Journal, 35(10), 537-554.

Kumar, A.A., Nayak, D.V., \& Shekhar, V. (2018). Knowledge outlook of Indian consumers towards BHIM App. Indian Journal of Marketing, 48(3), 7-16.

Li, H., Ye, Q., \& Law, R. (2013). Determinants of customer satisfaction in the hotel industry: An application of online review analysis. Asia Pacific Journal of Tourism Research, 18(7), 784-802.

Liébana-Cabanillas, F., Muñoz-Leiva, F., \& Sánchez-Fernández, J. (2018). A global approach to the analysis of user behavior in mobile payment systems in the new electronic environment. Service Business, 12(1), 25-64.

Liébana-Cabanillas, F., Sánchez-Fernández, J., \& Muñoz-Leiva, F. (2014a). Antecedents of the adoption of the new mobile payment systems: the moderating effect of age. Computers in Human Behavior, 35, 464-478. 
International Journal of Mathematical, Engineering and Management Sciences

Vol. 5, No. 1, 120-135, 2020

https://doi.org/10.33889/IJMEMS.2020.5.1.011

Liébana-Cabanillas, F., Sánchez-Fernández, J., \& Muñoz-Leiva, F. (2014b). The moderating effect of experience in the adoption of mobile payment tools in virtual social networks: the m-payment acceptance model in virtual social networks (MPAM-VSN). International Journal of Information Management, 34(2), 151-166.

Lu, Y., Yang, S., Chau, P.Y., \& Cao, Y. (2011). Dynamics between the trust transfer process and intention to use mobile payment services: a cross-environment perspective. Information \& Management, 48(8), 393-403.

Mallat, N. (2007). Exploring consumer adoption of mobile payments-A qualitative study. The Journal of Strategic Information Systems, 16(4), 413-432.

Massoth, M., \& Bingel, T. (2009, May). Performance of different mobile payment service concepts compared with a NFC-based solution. In 2009 Fourth International Conference on Internet and Web Applications and Services (pp. 205-210). IEEE. Venice, Italy.

Mauri, A.G., \& Minazzi, R. (2013). Web reviews influence on expectations and purchasing intentions of hotel potential customers. International Journal of Hospitality Management, 34, 99-107.

Morosan, C., \& DeFranco, A. (2016). It's about time: revisiting UTAUT2 to examine consumers' intentions to use NFC mobile payments in hotels. International Journal of Hospitality Management, 53, 17-29.

Oliveira, T., Thomas, M., Baptista, G., \& Campos, F. (2016). Mobile payment: Understanding the determinants of customer adoption and intention to recommend the technology. Computers in Human Behavior, 61, 404-414.

Passah, D.R.S., \& Kumar, A. (2019). Cashless economy and digitalization of tourism \& hospitality practices in India. Proceedings of 10th International Conference on Digital Strategies for Organizational Success. Available at SSRN: https://ssrn.com/abstract=3308586 or http://dx.doi.org/10.2139/ssrn.3308586

Rogers, E.M. (1983). Diffusion of innovations. The Free Press, New York.

Shankar, A., \& Datta, B. (2018). Factors affecting mobile payment adoption intention: an Indian perspective. Global Business Review, 19(3_suppl), S72-S89.

Shaw, N. (2014). The mediating influence of trust in the adoption of the mobile wallet. Journal of Retailing and Consumer Services, 21(4), 449-459.

Sheetal, J.U., Purohit, D., \& Anup, V. (2019). Increase in number of online services and payments through mobile applications post demonetization. Advances in Management, 12(1), 34-38.

Sinha, M., Majra, H., Hutchins, J., \& Saxena, R. (2019). Mobile payments in India: the privacy factor. International Journal of Bank Marketing, 37(1), 192-209.

Sivathanu, B. (2019). Adoption of digital payment systems in the era of demonetization in India: an empirical study. Journal of Science and Technology Policy Management, 10(1), 143-171.

Slade, E., Williams, M., Dwivedi, Y., \& Piercy, N. (2015). Exploring consumer adoption of proximity mobile payments. Journal of Strategic Marketing, 23(3), 209-223.

Slade, E.L., Dwivedi, Y.K., Piercy, N.C., \& Williams, M.D. (2015). Modeling consumers' adoption intentions of remote mobile payments in the United Kingdom: extending UTAUT with innovativeness, risk, and trust. Psychology \& Marketing, 32(8), 860-873.

Thakur, R. (2013). Customer adoption of mobile payment services by professionals across two cities in India: an empirical study using modified technology acceptance model. Business Perspectives and Research, 1(2), 17-30. 
International Journal of Mathematical, Engineering and Management Sciences

Vol. 5, No. 1, 120-135, 2020

https://doi.org/10.33889/IJMEMS.2020.5.1.011

Thakur, R., \& Srivastava, M. (2014). Adoption readiness, personal innovativeness, perceived risk and usage intention across customer groups for mobile payment services in India. Internet Research, 24(3), 369-392.

Thomas, R., \& Chatterjee, A. (2017). Unified payment interface (UPI): a catalyst tool supporting digitalization-utility, prospects \& issues. International Journal of Innovative Research and Advanced Studies, 4(2), 192-195.

Venkatesh, V., \& Davis, F.D. (2000). A theoretical extension of the technology acceptance model: four longitudinal field studies. Management Science, 46(2), 186-204.

Venkatesh, V., Morris, M.G., Davis, G.B., \& Davis, F.D. (2003). User acceptance of information technology: toward a unified view. MIS Quarterly, 27(3), 425-478.

Wen, J., Hu, Y., \& Kim, H.J. (2018). Impact of individual cultural values on hotel guests' positive emotions and positive eWOM intention: extending the cognitive appraisal framework. International Journal of Contemporary Hospitality Management, 30(3), 1769-1787.

Xiang, Z., Schwartz, Z., \& Uysal, M. (2015). What types of hotels make their guests (un) happy? Text analytics of customer experiences in online reviews. In I. A. Tussyadiah I. (Ed.), Information and Communication Technologies in Tourism, pp. 33-45. Springer, Cham.

Yang, S., Lu, Y., Gupta, S., Cao, Y., \& Zhang, R. (2012). Mobile payment services adoption across time: an empirical study of the effects of behavioral beliefs, social influences, and personal traits. Computers in Human Behavior, 28(1), 129-142.

Yang, Y., Liu, Y., Li, H., \& Yu, B. (2015). Understanding perceived risks in mobile payment acceptance. Industrial Management \& Data Systems, 115(2), 253-269.

Yang, Y., Park, S., \& Hu, X. (2018). Electronic word of mouth and hotel performance: a meta-analysis. Tourism Management, 67, 248-260.

Zhou, L., Ye, S., Pearce, P.L., \& Wu, M.-Y. (2014). Refreshing hotel satisfaction studies by reconfiguring customer review data. International Journal of Hospitality Management, 38, 1-10.

Zhou, T. (2013). An empirical examination of continuance intention of mobile payment services. Decision Support Systems, 54(2), 1085-1091.

\section{Links and websites}

International, C. (2018). 2019, from http://www.cuts-ccier.org/PaymentsInfrastructure/pdf/Level_The_Playing_Field_To_Leverage_The_Potential.pdf

cio.in. (2018). Retrieved May, 2018, from http://www.cio.in/feature/2018-era-mobile-commerce-and-epayments.

statista. (2018). Retrieved August, 2018, from https://www.statista.com/statistics/266119/india-retailmcommerce-sales/

economictimes.com. (2018). Retrieved $\quad$ December, 2018, from https://retail.economictimes.indiatimes.com/news/industry/405- 8-mn-upi-transactions-worth-rs59835-cr-clocked-in-sept-2018/66029694

inc42.com. (2018).Retrieved December, 2018, from https://inc42.com/buzz/upi-app-bhim-records-16-3mn-transactions-in-june-2018/

economictimes.com. (2019). Retrieved January, 2019, from https://economictimes.indiatimes.com/tech/software/india-becomes-worlds-fastest-growing-marketfor-apps/articleshow/63740547.cms 
International Journal of Mathematical, Engineering and Management Sciences

Vol. 5, No. 1, 120-135, 2020

https://doi.org/10.33889/IJMEMS.2020.5.1.011

Express, F. (2018). Retrieved January, 2019, from https://www.financialexpress.com/opinion/modigovernments-six-point-action-plan-to-boost-digital-transactions/1174867/ 